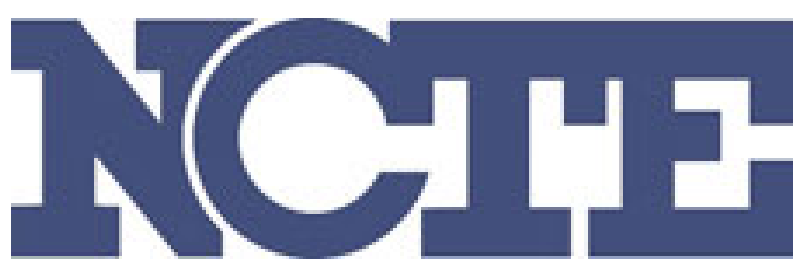

A Humanistic Rationale for Technical Writing Author(s): Carolyn R. Miller

Source: College English, Vol. 40, No. 6 (Feb., 1979), pp. 610-617

Published by: National Council of Teachers of English

Stable URL: http://www.jstor.org/stable/375964

Accessed: 16/03/2014 15:53

Your use of the JSTOR archive indicates your acceptance of the Terms \& Conditions of Use, available at http://www.jstor.org/page/info/about/policies/terms.jsp

JSTOR is a not-for-profit service that helps scholars, researchers, and students discover, use, and build upon a wide range of content in a trusted digital archive. We use information technology and tools to increase productivity and facilitate new forms of scholarship. For more information about JSTOR, please contact support@ jstor.org.

National Council of Teachers of English is collaborating with JSTOR to digitize, preserve and extend access to College English. 


\section{A Humanistic Rationale for Technical Writing}

A Question arose, during a committee discussion in our English department last year, whether students in our large technological university should be permitted to take a technical writing course to satisfy humanities requirements of their own schools and departments. ${ }^{1}$ There were two opinions among those in my department with whom I talked. Those who teach literature believed that students should not satisfy a humanities, or "English," requirement with a technical writing course. And our department should prevent them from doing so by instituting a literature prerequisite for the technical writing course. Those of us who teach technical writing responded differently. Mostly, we were baffled. Obviously we did not welcome what we considered an irrelevant prerequisite for our course, and we did not like the idea of our course being held hostage for the overstaffed literature courses. But were we willing to argue, indeed, could we argue that technical writing has humanistic value?

I believe that the argument can be made, and on firm and respectable grounds. But the way to it is not clear. The reasoning is obscured by a tradition of thought in both the sciences and the humanities, a tradition which has become a tacit understanding, a form of common sense. Making the argument requires articulating some new notions of what science is and does and some corresponding new notions of what technical and scientific rhetoric can be and do. I wish to argue that the common opinion that the undergraduate technical writing course is a "skills" course with little or no humanistic value is the result of a lingering but pervasive positivist view of science. In this view, human knowledge, of which we may take science to be a model, is a matter of getting closer to the material things of reality and farther away from the confusing and untrustworthy imperfections of words and minds. Technical and scientific rhetoric becomes the skill of subduing language so that it most accurately and directly transmits reality. It aims at being an efficient way of coercing minds to submit to reality.

Because the positivist view has supported both the rhetoric we call scientific and

${ }^{1}$ The question proved moot, for the university curriculum committee had previously decided that technical writing could not be allowed to serve as a humanities course.

Carolyn R. Miller is an instructor in the Department of English at North Carolina State University in Raleigh, where she teaches composition and technical writing, and a doctoral candidate in Communication and Rhetoric at Rensselaer Polytechnic Institute. She has published bibliographies on the teaching of technical writing, an essay in The Technical Writing Teacher, and has an article fortbcoming in the Central States Speech Journal on the rbetorical etbos of technology. 
that we call technical and provides no systematic way to distinguish the two, in this essay I begin by treating them together. I shall first summarize the main features of positivist science and illustrate how this view of science pervades the way we define and evaluate technical writing. I shall attribute some of our pedagogical problems to the positivist legacy. Then I shall sketch the new thinking in the philosophy of science and suggest its particular relevance for technical writing. Finally, I shall be able to suggest how this altered view of science, and of the relationship between science and rhetoric, can provide a basis for seeing technical writing as a more humanistic and less coercive endeavor.

Let me illustrate some common notions about technical and scientific rhetoric with a passage from an article entitled, "How Rhetoric Confuses Scientific Issues":

Rhetoric is defined as language designed to persuade or impress; the word may be considered a euphemism for loaded language. . . . Anyone who is convinced that only facts should persuade must, logically, condemn such rhetoric in the scientific literature. Realistically, of course, rhetoric cannot be eliminated entirely. But its use can be constricted significantly, and both readers and writers should be on guard against this violation of scientific principles. . . . Since scientists agree that their observations and conclusions should be presented as objectively as possible, rhetoric should be avoided assiduously in scientific writing. ${ }^{2}$

Obviously, in this view, science and rhetoric are mutually exclusive. Science has to do with observation and logic, the only ways we have of approaching external, absolute reality. Rhetoric has to do with symbols and emotions, the stuff of uncertain, incomplete appearances.

The technical writing textbooks are suffused with this view of both science and rhetoric. Some typical examples: "Technical writing is expected to be objective, scientifically impartial, utterly clear, and unemotional.... Technical writing is concerned with facts and the careful, honest interpretation of these facts." 3 Another: "Since technical writing is by definition a method of communicating facts it is absolutely imperative to be clear. . . . The point of view should be scientific: objective, impartial, and unemotional."4 And again: "Technical communication has one certain clear purpose: to convey information and ideas accurately and efficiently." 5 And finally: "Because the focus is on an object or a process, the language is utilitarian, emphasizing exactness rather than elegance. . . Technical writing is direct and to the point." 6 These characterizations have in common a conviction that content (that is, ideas, information, facts) is wholly separable from words. They all presuppose what has been called the "windowpane theory of language": the notion that language

\footnotetext{
${ }^{2}$ Barbara G. Cox and Charles G. Roland, IEEE Transactions on Professional Communication, PC-16 (Sept. 1973), 140.

${ }^{3}$ Thomas E. Pearsall, Teaching Technical Writing: Methods for College English Teachers (Washington, D.C.: Society for Technical Communication, 1975), p. 1.

${ }^{4}$ Gordon H. Mills and John A. Walter, Technical Writing, 4th ed. (New York: Holt, Rinehart, and Winston, 1978), p. 7.

${ }^{5}$ Joseph N. Ulman, Jr., and Jay R. Gould, Technical Reporting, 3rd ed. (New York: Holt, Rinehart, and Winston, 1972), p. 5.

${ }^{6}$ Charles T. Brusaw, Gerald J. Oliu, and Walter E. Alred, Handbook of Technical Writing (New York: St. Martin's Press, 1976), p. 475.
} 
provides a view out onto the real world, a view which may be clear or obfuscated. ${ }^{7}$ If language is clear, then we see reality accurately; if language is highly decorative or opaque, then we see what is not really there or we see it with difficulty.

This way of talking about technical writing is the legacy of what I am going to call for convenience the positivist view of science. ${ }^{8}$ This is a complex and varied tradition, extending in some forms back to the ancient Greek philosophers, but reaching its most extreme expression in the logical positivism of the early twentieth century. Put simply, positivism is the conviction that sensory data are the only permissible basis for knowledge; consequently, the only meaningful statements are those which can be empirically verified. Sense data are correlated and systematized by logical (mathematical) means and culminate in lawlike generalizations. Scientific laws are thus nothing more than shorthand summaries of sensory observations. Theoretical terms, or mathematical symbols, must be explicitly defined in terms of sense data and are, in effect, abbreviations for phenomenal descriptions.

Since sense impressions must initially be described in some language, much effort has been expended in the attempt to devise a pure "observation language," free of the emotion and metaphysics which pollute ordinary language. Ideally, scientific discourse would consist of "observation sentences" using only logical terms and observation terms, or of assertions using theoretical terms explicitly defined by reference to the observation terms. ${ }^{9}$ The culmination of this view of science and language was the attempt by Whitehead and Russell in Principia Matbematica to express the empirical content of science in the formulas of classical mathematics, to do away with ordinary language altogether and rely on the rock of logic. ${ }^{10}$ Korzybski's Science and Sanity and the General Semantics movement subscribe to a similar conviction.

Such a view of science presupposes a mechanistic and materialistic reality. The goal of human knowledge is direct apprehension of that reality. Facts are selfevident entities existing out there in the real world-we have only to learn how to see them accurately or derive them logically. Objectivity on the part of the observer minimizes personal and social interference, reducing observation to the accurate recording of the self-evident; formal logic represents the underlying structure of mechanistic reality. Truth, then, is the correspondence of ideas to reality, and proof is the logical demonstration of that correspondence. ${ }^{11}$ Science, which arrives at proven knowledge, is that process of demonstration, proceeding in Cartesian fashion by logical deduction from the self-evident.

In this epistemology, language, based as it is in personal psychology, is largely a

\footnotetext{
${ }^{7}$ See James L. Kinneavy, A Theory of Discourse (Englewood Cliffs, N.J.: Prentice-Hall, 1971), p. 39; also Joseph Gusfield, "The Literary Rhetoric of Science: Comedy and Pathos in Drinking Driver Research," American Sociological Review, 41 (February 1976), 16-34.

${ }^{8}$ More technically known as the Received View; tor a full discussion see Frederick Suppe, The Structure of Scientific Theories, 2nd ed. (Urbana: University of Illinois Press, 1977), chs. 1-3.

${ }^{9}$ Suppe, p. 15.

${ }^{10} \mathrm{~J}$. Bronowski, "Humanism and the Growth of Knowledge," in A Sense of the Future (Cambridge, Mass.: MIT Press, 1977), p. 74.

${ }^{11}$ Two relevant discussions of the philosophies involved here $\rightarrow \rightarrow$ Barry Brummett, "Some Implications of 'Process' or 'Intersubjectivity': Postmodern Rhetoric," Philosophy and Rhetoric, 9 (1976), 21-51; and C. Perelman and L. Olbrechts-Tyteca, The New Rhetoric (Notre Dame, Ind.: University of Notre Dame Press, 1969), esp. pp. 1-10, 509-14.
} 
distraction for science; and rhetoric is just irrelevant, because conclusions follow necessarily from the data of observation and the procedure of logic. Aristotle would have agreed: rhetoric, he said, has to do with "things about which we commonly deliberate-things for which we have no special art or science ... things as appear to admit of two possibilities."12 Rhetoric relies upon "artistic proofs," those which are created by the art of the speaker or writer. Science has to do with what Aristotle called "inartistic proofs," facts or artifacts which exist independently of human intentions and emotions and about which deliberation is unnecessary. Inartistic proofs are those which have only to be found; they are just there-self-evident and real and objective.

The most uncomfortable aspect of this non-rhetorical view of science is that it is a form of intellectual coercion: it invites us to prostrate ourselves at the windowpane of language and accept what Science has demonstrated. After all, if we do not see the self-evident, there must be something very wrong with us. I believe that this mystique of absolute scientific truth is as much responsible as our technical achievements for the power of science and technology in our culture today.

If rhetoric is irrelevant to science, technical and scientific writing become just a series of maneuvers for staying out of the way. A rhetorical discipline built on positivist theory must founder on this self-deprecation at its center. But because there has been no alternative basis for the discipline, technical writing as it is commonly taught is shot through with positivist assumptions, which destroy its aspirations toward disciplinary respectability and relegate it to its status as a skills course. I want to discuss four features of technical writing pedagogy which seem to me to illustrate problems due to this positivist legacy: unsystematic definitions of technical writing, emphasis on style and organization, insistence on certain characteristics of tone, and analysis of audience in terms of "level."

Definition of the subject has been a continuing problem in the teaching of technical writing. The textbooks and pedagogical literature are rife with attempts, all very similar and none very satisfactory. ${ }^{13}$ Definition based on content seems at first obvious and then unworkable-no one is prepared to say which subjects are "technical." Engineering, certainly; science, of course; but linguistics? political theory? seventeenth-century music? urban planning? Reality doesn't come in packages clearly marked "technical" or "nontechnical." But perhaps any aspect of reality might be treated in a technical or nontechnical manner. To return to the windowpane analogy, definition in terms of the window itself may be more promising than definition in terms of what is outside. Such definitions often take the form of an appeal to absolute clarity, ${ }^{14}$ but clarity is a more elusive and less useful criterion

${ }^{12}$ Rhetoric, I, 2; see The Rhetoric of Aristotle, ed. Lane Cooper (Englewood Cliffs, N.J.: Prentice-Hall, 1932), p. 11.

${ }^{13}$ For attempts at systematic definition, see Mills and Walter, cited above, note 4, and W. Earl Britton, "What Is Technical Writing?: A Redefinition," in The Teaching of Technical Writing, ed. Donald H. Cunningham and Herman A. Estrin (Urbana, Ill.: National Council of Teachers of English, 1975), pp. 9-14.

${ }^{14} \mathrm{An}$ influential definition of this sort is Britton's: "The primary . . . characteristic of technical and scientific writing lies in the effort of the author to convey one meaning and only one meaning in what he says. That one meaning must be sharp, clear, precise. And the reader must be given no choice of meanings" (p. 11). The textbook definitions cited earlier are other examples. 
than we have believed. It provides no way to distinguish poorly executed technical writing from writing that is not technical writing. For instance, the prose that many people find least clear, and which is the subject of much popular complaint these days, is writing that few would hesitate to call "technical"-government reports, sociological studies, insurance policies. Clarity is not a useful criterion especially if technical writing fails the test more often than other types of writing. Our definitions of technical writing leak badly. How can we teach a course, let alone develop a field of study, when we have no way to tell anyone what our subject matter is?

The second feature of our teaching that creates a problem is the emphasis on form and style at the expense of invention. ${ }^{15}$ The collapse of invention as a rhetorical canon is complementary to the rise of empirical science. If the subject matter of science (bits of reality, inartistic proofs) exists independently, the scientist's duty is but to observe clearly and transmit faithfully. The whole idea of invention is heresy to positivist science-science does not invent, it discovers. Form and style become techniques for increasingly accurate transmission of logical processes or of sensory observations; consequently, we teach recipes for the description of mechanism, the description of process, classification, the interpretation of data. And, as one text indicates, stylistic problems are understood to result from the complexity of technical subject matter: the intricacy of that reality out there makes it difficult for me to transmit it accurately, to make my windowpane sufficiently transparent that you may see the details clearly. If we take this approach to form and style very seriously, there is not very much to teach in a technical writing class. Form and style become, in theory, as self-evident as content. ${ }^{16}$ No wonder that technical writing is a course that anyone can teach and no one wants to teach. But why is it that students have difficulty writing effective prose if all they are doing is transmitting a reality about which they know more than the technical writing teacher?

A third problematic feature of our teaching is the insistence on certain characteristics of tone: be objective, be unemotional, be impersonal. These injunctions directly implement the positivist epistemology. But technical writing teachers are consequently always grappling with the dilemma that English syntax does not handle impersonality very gracefully. Under the sway of positivism, scientists adopted as conventions the obvious stylistic means for staying out of the way of the subject matter-third person constructions, personifications, passive voice. ${ }^{17}$ Does it make sense to place a double burden on students by urging them to be impersonal on the one hand, but denying them, in the name of stylistic grace, these obvious syntactic tools on the other?

The fourth feature which our teaching owes to positivism is the tendency to analyze audiences in terms of "levels," as though we are concerned with how tall

\footnotetext{
${ }^{15}$ This lack of interest in invention is, of course, consistent with the tradition of teaching composition; it may be traced to Renaissance rhetorical theory (Ramism), which is the complement of Cartesian and Baconian science.

${ }^{16}$ The notion that form is self-evident may be related to the tendency for technical writing to be a listing of facts whose significance is supposed to go without saying; George Douglas has called this "cobblestone writing" in his recent article in The Tecbnical Writing Teacher, 5 (Fall 1977), 18-21.

${ }^{17}$ It is interesting that the social sciences, which still place a great deal of stock in positivism, adhere more strictly to impersonal stylistic forms than do the biological and physical sciences; compare, for example, the preferences on the use of the first person pronoun in the style manuals of the American Psychological Association and the Council of Biology Editors.
} 
they have to be to look out of our window. Some audiences are capable of seeing some aspects of reality; others are more capable and can see more. Technical writing is sometimes characterized by its particular concern for audience analysis, but the positivist legacy encourages us to analyze only the relationship between the reader and the reality (and whether the reader is mentally adequate to the reality). As a result, audience adaptation too often becomes an exercise in vocabulary. If audience adaptation is to be central to technical writing, we need broader and more flexible methods which will permit analysis of the relationship between the writer and the reader. For we have not said anything very useful about the writer-reader relationship when we say that the purpose in technical writing is to be clear. Why has it been so difficult in a technical writing class to talk about the relationship between writer and readers and the reasons for saying anything about a subject in the first place?

Scientists, engineers, teachers of technical writing, and their students tacitly share the positivist theory about the role of rhetoric in science. Consequently, students look upon writing as a superfluous, bothersome, and usually irrelevant aspect of their technical work. I submit that our teaching reinforces that attitude. We encourage students to see writing as a necessary evil, necessary primarily because it is an amenity occasioned by the conditions of employment in business or industry. We teach writing as the ex post facto expression of a scientific idea or a technical effort, not as part of that idea or that effort.

My real point here is that although our thinking about technical writing seems to be heavily indebted to the positivist view of science (and of rhetoric), this view is no longer held by most philosophers of science or by most thoughtful scientists. Among the major objections to the theory are the complete failure of attempts to devise an observation language, the inability of theoretical terms defined as summaries of known effects to account for new effects observed later, the failure to account for the growth and change of scientific knowledge, and the serious limitations of logical systems. ${ }^{18}$ In addition, a new epistemology, based on modern developments in cultural anthropology, cognitive psychology, and sociology, has challenged the positivist conception of knowledge. This new epistemology makes human knowledge thoroughly relative and science fundamentally rhetorical.

This epistemology has been developed at length in the journals of rhetoric and philosophy, and I will not attempt a full discussion here. ${ }^{19}$ Briefly summarized, it holds that whatever we know of reality is created by individual action and by communal assent. Reality cannot be separated from our knowledge of it; knowledge cannot be separated from the knower; the knower cannot be separated from a community. Facts do not exist independently, waiting to be found and collected and systematized; facts are human constructions which presuppose theories. We bring to the world a set of innate and learned concepts which help us select, organize, and understand what we encounter.

\footnotetext{
${ }^{18}$ See Suppe, ch. 4.

${ }^{19}$ See especially Michael C. Leff, "In Search of Ariadne's Thread: A Review of the Recent Literature on Rhetorical Theory," Central States Speech Journal, 29 (Summer 1978), 73-91, for a survey of this epistemic view of rhetoric.
} 
Science, then, is not concerned directly with material things, but with these human constructions, with symbols and arguments. Scientific observation relies on tacit conceptual theories, which may be said to "argue for" a way of seeing the world. Scientific verification requires the persuasion of an audience that what has been "observed" is replicable and relevant. And logical procedure, as Thomas Kuhn has shown, is inadequate to account for scientific growth and change. ${ }^{20}$ Science is, above all, a communal enterprise; it is, according to John Ziman, unique among the "faculties" in insisting on consensus. ${ }^{21}$ Truth, or the knowledge for which science seeks, is thus the correspondence of ideas, not to the material world, but to other people's ideas. Certainty is found not in isolated observation of nature or in logical procedure but in the widest agreement with other people. Science is, through and through, a rhetorical endeavor.

It is the contention of this essay that we can improve the teaching and study of technical writing by trading our covert acceptance of positivism for an overt consensualist perspective. For one thing, as I have tried to show, our pedagogy is weakened by submerged inconsistencies and contradictions, which I attribute to an unthinking acceptance of positivist science. For another, we can stop engaging in and submitting to the intellectual tyranny to which our tacit epistemology has led us. Science understood as apodictic demonstration demands acknowledgement, an act of submission by the audience. Science understood as argument asks for assent, for an act of will on the part of the audience. Good technical writing becomes, rather than the revelation of absolute reality, a persuasive version of experience. To continue to teach as we have, to acquiesce in passing off a version as an absolute, is coercive and tyrannical; it is to wrench ideology from belief. Much of what we call technical writing occurs in the context of government and industry and embodies tacit commitments to bureaucratic hierarchies, corporate capitalism, and high technology. If we pretend for a minute that technical writing is objective, we have passed off a particular political ideology as privileged truth. ${ }^{22}$

Finally, if we revise the understanding of science that underlies our teaching, we may be able to reconceptualize our entire discipline in a more systematic way. I am not prepared to offer a complete reconceptualization here and now. There are many promising trends in the texts and the teaching literature, and growing awareness of the problems will help to change the way we teach and talk about technical and scientific writing. ${ }^{23}$ But I would like to suggest a general approach to rethinking our

\footnotetext{
${ }^{20}$ The Structure of Scientific Revolutions, 2nd ed. (Chicago: University of Chicago Press, 1970). 13.

${ }^{21}$ Public Knowledge: The Social Dimension of Science (Cambridge: Cambridge University Press, 1968), p.

${ }^{22}$ For a critique of this problem in the area of technology assessment, see B. Wynne, "The Rhetoric of Consensus Politics: A Critical Review of Technology Assessment," Research Policy, 4 (March 1975), 10858.

${ }^{23}$ Recent discussions that explicitly recognize the rhetorical character of scientific and technical writing are: Dennis R. Hall, "The Role of Invention in Technical Writing," The Technical Writing Teacher, 4 (Fall 1976), 13-24; Dwight W. Stevenson, "Toward a Rhetoric of Scientific and Technical Discourse," The Technical Writing Teacher, 5 (Fall 1977), 4-10; S. Michael Halloran, "Eloquence in a Technological Society," Central States Speech Journal (forthcoming); and S. Michael Halloran, "Technical Writing and the Rhetoric of Science," Journal of Technical Writing and Communications, 8 (1978), 77-88.
} 
discipline along the lines of the new rhetoric. This approach will also provide a way of distinguishing scientific from technical rhetoric, an issue which this essay has avoided until now. We can begin with a sociological and rhetorical truism: communication occurs in communities. Scientists form an epistemic community, consisting of smaller and overlapping disciplinary subcommunities. We can define scientific writing as written communication based within a certain community and undertaken for certain communal reasons. Technical writing occurs within a somewhat different community for somewhat different reasons.

The scientific community's objectives, methods, and values have been widely discussed. Bronowski, Kuhn, and Ziman, for example, have much to contribute to an understanding of the reasons and conditions for communication in science. Very little has been accomplished, however, to provide a similar characterization of the technological community and its rhetoric. My own hunch is that we should look in the direction of organizational and management theory, the sociology of technology, and the cultural history of industry and bureaucracy. These areas may provide a basis for distinguishing the reasons and values which underlie the rhetoric of technical writing.

Under this communalist perspective, the teaching of technical or scientific writing becomes more than the inculcation of a set of skills; it becomes a kind of enculturation. We can teach technical or scientific writing, not as a set of techniques for accommodating slippery words to intractable things, but as an understanding of how to belong to a community. To write, to engage in any communication, is to participate in a community; to write well is to understand the conditions of one's own participation-the concepts, values, traditions, and style which permit identification with that community and determine the success or failure of communication. Our teaching of writing should present mechanical rules and skills against a broader understanding of why and how to adjust or violate the rules, of the social implications of the roles a writer casts for himself or herself and for the reader, and of the ethical repercussions of one's words. We can thus ground our teaching and our discipline in a communal rationality rather than in contextless logic. Under this flagrantly rhetorical approach, the subject matter, syllabi, and assignments in a technical writing course may not change very much. But our attitudes might, and so might those of our students and colleagues.

Finally, let me return to my original problem, the humanities requirement. If we do begin to talk about understanding, rather than only about skills, I believe we have a basis for considering technical writing a humanistic study. The examination and understanding of one's own activity and consciousness, the "return of consciousness to its own center," is, as Walter Ong has suggested, the central impulse of the humanities. ${ }^{24}$ I maintain that a course in scientific or technical writing can profitably be based upon this kind of self-examination and self-consciousness, and that, in fact, the rhetorical approach demands such a basis. It might, in addition, contribute to a more fruitful appreciation and critical understanding of two central forces in our culture, science and technology themselves.

${ }^{24}$ Rhetoric, Romance, and Tecbnology (Ithaca, N.Y.: Cornell University Press, 1971), p. 304. 